of "use" - and the tendency-or the disposition-or the instinctto use ? The answer may be, and perhaps always must be, that the possibility of each new use, and the disposition to it, has been acquired from the evolution of elements inherent in the germ.

The next specimen of pure scientific reasoning which I find in Mr. Dyer's letter is involved in his rebuke to me for having made an assertion in support of which I have produced no "definite observed evidence." That assertion he correctly quotes thus:- "All organs do actually pass through rudimentary stages in which actual use is impossible." He challenges me for proof. I return the challenge, and summon Mr. Dyer to produce one single instance of any animal which does NOT pass through such stages. It is the universal law of all organic beings. In some germ-in some bud-in some egg -in some womb, every living thing begins to grow. Moreover, what is true of it as a whole, is true of all its parts. All its organs-be they few and simple, or many and complex-pass through stages of incipience, of impotence- of divorce from even the possibility of actual and present use. It is truly an astonishing circumstance that any scientific man should ask for any proof of this. It is a signal illustration of the power of reglected elements in reasoning-of the familiar becoming the practically unknown, because it is the unconsidered.

Possibly, Mr. Dyer may say that he did not understand me to make the assertion of each individual organism. But this is a distinction without a difference. If the Darwinian theory be true, there has never been any other origin for species than the origin of a few first germs--developed ever since by the processes of ordinary generation, through a succession of individuals. The well-known generalization of Darwinian embryologists is that the foetal development of the individual organism is the type and repetition of the development of species in the womb of time. In the doctrine of "prophetic germs," which he quotes as mine, nothing is mine except, perhaps, the adoption of the words. It is the embodiment, in what I hold to be accurate and appropriate language, of the most familiar facts in nature, and of the intellectual conceptions which are their necessary counterpart in mind.

There is one consequence necessarily following from this conception, which is seldom thought of and never fully accepted or recognized; and that is, that, if every organism has been developed from older organisms by very slow and gradual and minute changes through unnumbered ages, there must have been a constant succession of new organs coming on, along with an equally constant succession of other organs passing off. I see no escape from this conclusion. Yet if it be true, nothing can be more unreasonable than to wonder at the occurrence of structures which are divorced from actual use, and which are variously called "rudimentary," or " aborted." The common interpretation always is that they are the inherited remains of structures which have been once in full use, and have been lost by the atrophy of disuse. This may or may not be true, according to special facts in each case. But that there has always been in time past a series of incipient structures on the rise for actual use in future generations of development is a necessary consequence of the Darwinian hypothesis, and indeed of all other forms of pure evolutionism. The only escape from it is the supposition that special organs may have arisen suddenly - may have advanced rapidly into functional use - as rapidly as a caterpillar rushes into the structure of a butterfly, after a short interval of inactivity or sleep.

This is possible-this is at least conceivable. Nay more, this may have been the process by which new species have been introduced. But this is not Darwinism. The occasional introduction of new germs, with new potentialities, and the "hurrying up" of these through rapid stages of development, or of hatching, is an idea which, if I remember right, did not escape the speculative glance of Darwin. But it was too incongruous to be easily assimilated with his special formulæ, and so his fine eye glanced off it again, after only a momentary look; and at a later date he was so biassed in favour of the mechanics of fortuitous variation that he came to regard the very idea of development being guided towards any use yet lying wholly in the future as incompatible with his theory, and indeed destructive of it.

Mr. Dyer says that there was nothing in my last letter " which has not been worn threadbare by discussion." If so, it seems a pity that Mr. Dyer should have interposed in a discussion which he thinks exhausted. This impression may account for the poverty of the contribution made by an able man to a subject which is perhaps the most difficult, the most interesting, and the most far-reaching which can engage the human understanding.

Inveraray, January 19.

\section{Multiple Resonance obtained with Hertz's Vibrators.}

WhILE Mr. Trouton and I were carrying out some experiments to try and drive an independent current through the arc formed when a spark passes in a Hertzian resonating receiver, we succeeded to some extent in doing so, but obtained an unexpected result which may be of service to others working upon this matter. We found that if the two sides of the receiver be connected with a delicate galvanometer, it is affected whenever a spark passes. It is not so easy to get sparks to pass when the galvanometer is so connected as when the receiver is insulated; but whenever a spark passes, the galvanometer-a 7000-ohm Cambridge Scientific Instrument Company's pattern-is deflected through several degrees and often off the scale. It is not very easy to see how the action takes place, because one would imagine that an electro-dynamometer would be required. The current is reversed along with the reversal of the primary induction, and seems to be connected with the direction of the electromagnetic impulse that first breaks down the air-space in the receiver: an explanation founded upon this consideration explains the facts so far, but further investigation is required to fully confirm it. We have found this method of observing the Hertzian phenomena, which we have worked successfully with an apparatus giving a wave-length of 0.6 metre, much more satisfactory than the method founded on utilizing the conductivity of the spark as a path to drive an independent current either across or along. Some experiments in a vacuum tube, however, showed that this method is capable of extension. We found it also more satisfactory than a bolometer method, which, however, worked fairly well. For this we interposed, instead of the sparkgap, a very fine wire, which was made into one of the arms of a Wheatstone's bridge. The great desideratum was a very fine wire, and we intend trying silvered quartz fibres if we can obtain them, and lead drawn inside glass, \&c., our hearts having been broken trying to use that brittle beauty, Wollaston wire.

Any of these methods, in which your observing apparatus, the galvanometer, can be at a distance from the receiver, is more manageable than ones like that described by Mr. Gregory, in which the receiver is itself also the observing apparatus. We exhibited our method of observing the occurrence of spark by connecting the ends of the spark-gap with a delicate galvanometer at the meeting of the Dublin University Experimental Science Association last November.

Geo. Fras. FitzGerald.

January 25

As I see from a notice of the proceedings of the Academy of Sciences, Paris, in last week's NATURE (p. 287), that MM. Edouard Sarasin and Lucien de la Rive have observed the fact that "multiple resonance" can be obtained by using different sized resonators with a Hertzian "vibrator" I adjoin the following short account of experiments of a somewhat different character made during last autumn, which have led to the same results, and which were brought before the notice of the Dublin University Experimental Association last November. Since then I have learnt what these experimenters also seem not to have known - that some of Hertz's earlier experiments were more especially concerned with this very fact.

First, it was found that the wave-length in the Hertzian experiment of loop and nodes formed by reflection from a large metallic sheet had altered since the apparatus had been last used some months previously. This was attributed at first to something in the "vibrator," such as the width of the sparkgap; but ultimately, on remembering how an accident had necessitated a new resonator being made, the cause was recognized-namely, that it was not exactly the same size as the previous one; and when several resonators of different sizes were made, they were found to give the node at different distances from the reflecting sheet. The intensity of the sparking with which these were affected increased with their size up to a certain point, and then diminished. So that it seems as if a "vibrator" did not send out a "line spectrum," so to speak, but sends out a "band spectrum," the centre of which is the brightest. The period, then, of a "vibrator" is that belonging to the centre of this "band." 